\title{
Platelet profile and its correlation to paediatric patients with acute malaria in a tertiary care hospital
}

\author{
*Gurudutt Joshi ${ }^{1}$, Deepak Gamit ${ }^{2}$ \\ Sri Lanka Journal of Child Health, 2016; 45(2):107-110
}

\begin{abstract}
Introduction: Few studies are available as regards status of platelets in malaria in paediatric patients.

Objectives: To correlate factors such as age, type of malaria species and degree of parasitaemia with the degree of thrombocytopenia and to correlate the mean platelet volume and platelet distribution width with the malaria species.
\end{abstract}

Method: A prospective observational study was conducted on patients 1 to 17 years of age admitted to the department of paediatrics of a tertiary level hospital from January 2014 to November 2014 with a history of acute fever (less than 5 days) and peripheral blood smear positive for malarial parasites with the rapid diagnostic test. A detailed history and examination of the patients along with the demographic profile was entered in the predesigned proforma. Automated Coulter haematology analyser (Abacus) was used for investigations. The data was analysed by SPSS 16 statistical analysis. Comparison among three groups of continuous data was done using a One-way ANOVA, whereas data not conforming to normal distribution were compared by a Kruskal-Wallis Test. Categorical data were compared using Pearson Chi-Square Test.

Results: There were 105 patients who met the inclusion criteria. Of them, $60 \%$ had vivax malaria, $33 \%$ had falciparum malaria and the rest had mixed malaria. Thrombocytopenia was present in $85 \%$, severe thrombocytopenia $(<50,000 / \mathrm{cu} \mathrm{mm})$ being

$\overline{{ }^{1} \text { Associate Professor, }{ }^{2} \text { Medical Officer, Department }}$ of Paediatrics, Surat Municipal Institute of Medical Education and Research, Surat, Gujarat, India

*Correspondence: joshigurudutt@yahoo.com

(Received on 19 July 2015: Accepted after revision on 18 September 2015)

The authors declare that there are no conflicts of interest

Personal funding was used for this project.

Open Access Article published under the Creative

Commons Attribution CC-BY (cc) (P) present in $36 \%$. The platelet count significantly correlated with the type of malaria and the degree of parasitaemia. The platelet count decreased as the age increased in moderate to severe thrombocytopenia. There was also correlation between the mean platelet volume but not the platelet distribution width and the malaria species.

Conclusion: Thrombocytopenia was present in $85 \%$ of patients, the degree of thrombocytopenia correlating significantly with the degree of parasitaemia and the type of malaria. The MPV but not the PDW correlated significantly with the type of malaria species.

(Key words: Malaria, thrombocytopenia, rapid diagnostic test, mean platelet volume, platelet distribution width).

DOI: http://dx.doi.org/10.4038/sljch.v45i2.8117

\section{Introduction}

India accounts for about $50 \%$ of the 2 million reported cases of malaria in the World Health Organization South-East Asia Region ${ }^{1}$. About $80 \%$ cases of malaria reported in India are confined to areas comprising $20 \%$ of the population residing in tribal, hilly, difficult and inaccessible areas ${ }^{2}$. Haematological abnormalities such as anaemia, thrombocytopenia and leucocytosis or leucopenia have been observed in patients with malaria ${ }^{3}$.

\section{Objectives}

To correlate factors such as age, type of malaria species and degree of parasitaemia with the degree of thrombocytopenia and to correlate the mean platelet volume (MPV) and platelet distribution width (PDW) with the malaria species.

\section{Method}

A prospective observational study was conducted on patients 1 to 17 years of age admitted to the department of paediatrics of a tertiary level hospital from January 2014 to November 2014 with a history of acute fever (less than 5 days) and peripheral blood 
smear positive for malarial parasites with the rapid diagnostic test (RDT). Patients with acute fever with RDT negative for malaria, those with chronic fever, only smear positive for plasmodium gametocytes, patients with signs and symptoms of acute viral fever, either on or had taken antimalarial treatment, were excluded from the study. A detailed history and examination of the patients including the type of fever and its duration, signs and symptoms suggestive of malaria along with the demographic profile was entered in the predesigned proforma. Basic screening for malaria was done by performing RDT using RDT kits (MALARIAGEN) available in the Institute. Venous blood was collected for haematological investigations. Automated Coulter haematology analyser (Abacus) was used for investigations. Peripheral blood smear was used for detection of malarial parasites and also for platelets wherever necessary. The data were analysed by SPSS 16 version for statistical analysis. A 'p' value $<0.05$ was taken as significant for statistical analysis. Comparison among three groups of continuous data was done using a One-way ANOVA, whereas data not conforming to normal distribution were compared by a Kruskal-Wallis Test. Categorical data were compared using Pearson Chi-Square Test.

\section{Results}

During the study period there were 105 patients who met the inclusion criteria. Of them, $60 \%$ had vivax malaria, $33 \%$ had falciparum malaria and the rest had mixed malaria. Sixty two percent were male. Thrombocytopenia was categorized as mild $(100,001-150,000 / \mathrm{cu} \mathrm{mm})$, moderate $(50,000-$ $100,000 / \mathrm{cu} \mathrm{mm})$ and severe $(<50,000 / \mathrm{cu} \mathrm{mm})$. Correlation of platelet counts with the type of malaria species is shown in Table 1 . This was statistically significant $(\mathrm{p}<0.05)$.

Table 1: Correlation of platelet counts with type of malaria species

\begin{tabular}{|lcccc|}
\hline Platelet count/cu mm & Plasmodium vivax & Plasmodium falciparum & Mixed & Total (\%) \\
$<50,000$ & 16 & 20 & 2 & $38(36.2)$ \\
$50,000-100,000$ & 23 & 7 & 1 & $31(29.5)$ \\
$100,001-150,000$ & 13 & 4 & 3 & $20(19.0)$ \\
$>150,000$ & 11 & 4 & 1 & $16(15.2)$ \\
\hline
\end{tabular}

Correlation of age with platelet counts in malaria is shown in Table 2. Platelet counts decreased as the age increased in moderate to severe thrombocytopenia in malaria. This was statistically significant $(\mathrm{p}<0.05)$.

Table 2: Correlation of age with platelet counts in malaria

\begin{tabular}{|lccc|}
\hline Platelet count/cu mm & $\mathbf{1 - 5}$ years & $\mathbf{6 - 1 0}$ years & $\mathbf{1 1 - 1 7}$ years \\
$<50,000$ & 05 & 11 & 22 \\
$50,000-100,000$ & 00 & 05 & 11 \\
$100,001-150,000$ & 08 & 04 & 08 \\
$>150,000$ & 03 & 07 & 21 \\
\multicolumn{1}{c}{ Total } & 16 & 27 & 62 \\
\hline
\end{tabular}

Mean platelet count (MPC) of the 105 malarial patients in the study was $84,653 \pm 63,592$. Correlation of the MPC with the degree of parasitaemia is shown in Table 3. There was an inverse correlation between the MPC and degree of parasitaemia which was statistically significant $(\mathrm{p}<0.05)$.

Table 3: Correlation of mean platelet count with

\begin{tabular}{|cc|}
\multicolumn{3}{c}{ degree of parasitaemia } \\
\hline Parasitaemia & Mean platelet count $/ \mathbf{c u} \mathbf{~ m m}$ \\
+1 & $128,385 \pm 72,315$ \\
+2 & $93,242 \pm 51,569$ \\
+3 & $70,133 \pm 76,187$ \\
+4 & $65,727 \pm 40,579$ \\
\hline
\end{tabular}

Correlation of MPV with the type of malaria species is shown in Table 4. Plasmodium Vivax had highest degree of correlation followed by Plasmodium Falciparum and mixed species respectively, all being statistically significant $(\mathrm{p}<0.05)$ 
Table 4: Correlation of mean platelet volume with type of malaria species

\begin{tabular}{|lccc|}
\hline \multicolumn{1}{c}{ Malaria species } & Mean platelet count (femtolitre-fL) & \multicolumn{2}{c|}{$\mathbf{9 5 \%}$ Confidence interval } \\
Plasmodium Vivax & $9.8825 \pm 0.66999$ & 8.7138 & 9.0513 \\
Plasmodium Falciparum & $7.5171 \pm 0.81403$ & 7.2375 & 7.7968 \\
Mixed & $8.5000 \pm 0.66833$ & 7.8819 & 9.1181 \\
\hline
\end{tabular}

However, correlations between MPC and age, severity of parasitaemia and severity of thrombocytopenia, splenomegaly and severity of thrombocytopenia, platelet distribution width (PDW) and type of malaria were not significant $(\mathrm{p}>0.05)$.

\section{Discussion}

This study was carried out in a tertiary hospital of industrial, urban and coastal city of Surat in Gujarat State of India. The urban population of Surat is about 4-4.5 million and consists of inhabitants from all over India. The average annual precipitation is around $150-200 \mathrm{~cm}$ per year and the city is an endemic and high risk zone for malaria. Thrombocytopenia is a common finding in several acute infective diseases including malaria ${ }^{4,5,6}$. In our study, thrombocytopenia was present in all types of malaria species which was similar to findings in other Indian studies ${ }^{7,8}$. However, severe thrombocytopenia was more common in falciparum malaria in our study. Thrombocytopenia was inversely proportional to age, the platelet count decreasing as the age of patients increased. Although severe thrombocytopenia was associated with a higher degree of parasitaemia $(+3$ to +4$)$, this was not statistically significant. Ladhani et al had similar results?

Though severe thrombocytopenia was present in $42 \%$ of the malaria patients in our study, there was no bleeding in any patient, similar findings being observed in studies by Shetty $S^{8}$ and Jadhav $U^{10}$. The reason for rare bleeding episodes in malaria may be the hypersensitive platelets, which are thought to enhance haemostatic responses which have been reported despite thrombocytopenia ${ }^{11,12,13}$. In a study by Chandra ${ }^{14}$ the MPV of more than $8 \mathrm{fL}$ was a comparatively more sensitive indicator for vivax malaria $(70.8 \%)$ than falciparum $(50.4 \%)$. Our findings were similar as we had MPV of $9.8 \mathrm{fL}$ in vivax malaria compared with a MPV of $7.5 \mathrm{fL}$ in falciparum malaria which was statistically significant $(p<0.05)$. In a study by Maina et al, MPV was more in patients with malaria than non malaria ${ }^{4}$. Nayar et al, in a study of patients aged 3-62 years from Tamilnadu (India) reported increase in both MPV and PDW in malaria patients with thrombocytopenia, compared to controls, which was statistically significant ${ }^{15}$. In the study by Chandra, PDW, in the range of $6-10$, was a more sensitive indicator for falciparum $(82.6 \%)$ than vivax $(69.5 \%)$ malaria ${ }^{14}$. In our study, PDW was 10.4 in vivax and 9.2 in falciparum malaria, which was not significant $(p>0.05)$. Although spleen enlargement was maximum $(42 \%)$ in severe thrombocytopenia, this was not statistically significant $(p>0.05)$ in our study.

\section{Conclusions}

- Thrombocytopenia was seen in $85 \%$ of malaria patients.

- Degree of thrombocytopenia correlated well with the degree of parasitaemia and the type of malaria species and this was statistically significant $(\mathrm{p}<0.05)$.

- The MPV but not the PDW correlated significantly $(p<0.05)$ with the malaria species.

\section{References}

1. World Health Organization. World Malaria Report 2013.Geneva: WHO, 2014. Available from:

http://www.who.int/malaria/publications/wo rld_malaria_report_2013/en/ [Accessed on March 3, 2015].

2. National vector born disease control programme [homepage on Internet] /Diseases/Malaria. Available from: http://nvbdcp.gov.in/malaria-new.html [accessed on March 3, 2015]

3. Guidelines for the treatment of malaria, $2^{\text {nd }}$ edition, 2010 [Monograph on the Internet]. Geneva: WHO Library Cataloguing-inPublication [Cited on March 3 2015]. Available from: http://www.who.int/malaria(publications/a to $\mathrm{z} / 9789241547925 / \mathrm{en} / \mathrm{index} . \mathrm{html}$

4. Maina R, Walsh D, Gaddy C, Hongo G, Waitumbi $\mathbf{J}$,Otieno L. Impact of plasmodium falciparum infection on haematological parameters in children living 
in western Kenya. Malaria Journal 2010; 9 (Suppl. 3):S4.

http://dx.doi.org/10.1186/1475-2875-9-S3-

S4

PMid: 21144084 PMCid: PMC3002140

5. Adedapo AD, Falade CO, Kotila RT, Ademowo GO. Age as a risk factor for thrombocytopenia and anaemia in children treated for acute uncomplicated malaria. Journal of Vector Borne Diseases 2007; 44: 266-77.

PMid: 18092534

6. Kaushik J, Gomber S, Dewan P. Clinical and epidemiological profiles of severe malaria in children from Delhi, India. Journal of Health, Population and Nutrition 2012; 30(1): 113-6.

http://dx.doi.org/10.3329/jhpn.v30i1.11291

7. Shyam Sunder B, Rao V, Prasad D, Shankaraiah K ,Reddy R, Pandit V. Haematological alterations in malaria patients with clinical correlation in a tertiary care hospital. International Journal of Biological and Medical Research 2013; 4(2): 3139-42.

8. Shetty G, Sreedhara K, Gonsalves S, Dany A, Rai B. Thrombocytopenia in children with malaria. A study from coastal Karnataka. Asia Pacific Journal of Tropical Diseases 2012; 4: 107-9.

http://dx.doi.org/10.1016/S22221808(12)60 026-7

9. Ladhani S, Lowe B, Cole A, Kowuondo K, Charles R, Newton J. Changes in white blood cells and platelets in children with falciparum malaria relationship to outcome. British Journal of Haematology 2002; 119:839-47.

http://dx.doi.org/10.1046/j.13652141.2002.0

3904.x

PMid: 12437669
10. Jadhav U, Patkar V, Kadam N. Thrombocytopenia in malaria- Correlation with type and severity of thrombocytopenia. Journal of the Association of Physicians of India 2004; 58(8): 615-8.

11. Geradin P, Rogier C, Ka As, Jouvencel P, Brousse V, Imbert P. Prognostic value of thrombocytopenia in African children with falciparum malaria. American Journal of Tropical Medicine and Hygiene 2002; 66: 686-91.

12. Kelton J, Keystone J, Moore J, Denomme G, Tozman E, Glynn M. Immune mediatedthrombocytopenia of malaria. Journal of Clinical Investigation 1983; 71: 826-32.

http://dx.doi.org/10.1172/JCI110836

PMCid: PMC436939

13. Moulin F, Lesage F, Legrose A, Maroga C. Thrombocytopenia and plasmodium falciparum malaria in children with different exposures. Archives of Disease in Childhood 2003; 88: 540-1.

http://dx.doi.org/10.1136/adc.88.6.540

PMid: 12765928 PMCid: PMC1763122

14. Chandra S, Harish S. Role of Haematological parameters as an indicator of acute malarial infection in Uttrakhand State of India. 2013. Mediterranean Journal of Hematology and Infectious Diseases 5(1); open journal system. Available from http://www.mjhid.org/issue/view/2013

[Accessed on March 3 2015].

15. Nayar S, Reddy M, Vjayshree R, Padmavathy F, Begum R, Arudra P. Haematological parameters including platelet indices in vivax and falciparum malaria. Chettinad Health City Medical Journal 2014; 3(3): 95-100. 